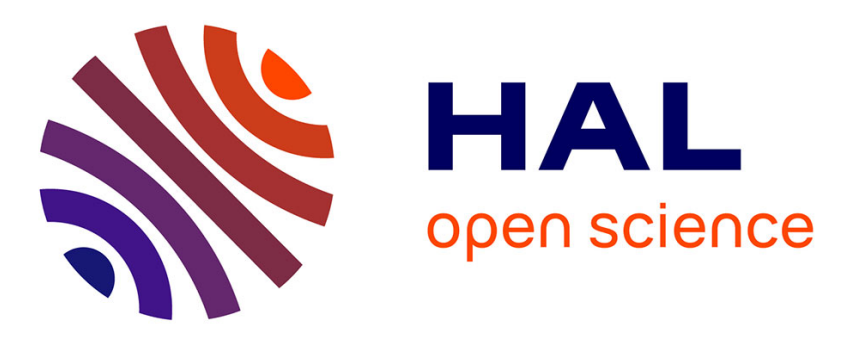

\title{
A dissociation between preserved abstract spatial knowledge and impaired navigation in a blind patient
}

Tal Seidel Malkinson, Raffaella Migliaccio, Hélène Migeot, Christine Picq, Antonio Cerrato, Pascale Pradat-Diehl, Paolo Bartolomeo, Monica N. Toba

\section{- To cite this version:}

Tal Seidel Malkinson, Raffaella Migliaccio, Hélène Migeot, Christine Picq, Antonio Cerrato, et al.. A dissociation between preserved abstract spatial knowledge and impaired navigation in a blind patient. Cortex, 2020, 128, pp.322-325. 10.1016/j.cortex.2020.03.017 . hal-02882346

\section{HAL Id: hal-02882346 https://hal.sorbonne-universite.fr/hal-02882346}

Submitted on 26 Jun 2020

HAL is a multi-disciplinary open access archive for the deposit and dissemination of scientific research documents, whether they are published or not. The documents may come from teaching and research institutions in France or abroad, or from public or private research centers.
L'archive ouverte pluridisciplinaire HAL, est destinée au dépôt et à la diffusion de documents scientifiques de niveau recherche, publiés ou non, émanant des établissements d'enseignement et de recherche français ou étrangers, des laboratoires publics ou privés. 


\section{A dissociation between preserved abstract spatial knowledge and im- paired navigation in a blind patient}

Tal Seidel Malkinson'1, Raffaella Migliaccio ${ }^{1}$, Hélène Migeot ${ }^{2}$, Christine Picq $^{2}$, Antonio Cerrato ${ }^{3}$, Pascale Pradat-Diehl2,4, Paolo Bartolomeo ${ }^{1}$, Monica N. Toba ${ }^{1,5}$

1Paris Brain Institute, ICM, Sorbonne Universités, UPMC Paris 06, Inserm UMR S 1127, CNRS UMR 7225, F-75013, \& IHU-A-ICM, Paris, France

${ }^{2}$ AP-HP, HxU Pitié-Salpêtrière-Charles-Foix, service de Médecine Physique et de Réadaptation \& PHRC Régional NEGLECT, Paris, France

3 University of Naples 'Federico II', Naples, Italy

${ }^{4}$ GRC-UPMC n ${ }^{\circ} 18$ - Handicap cognitif et réadaptation, Paris, France

${ }^{5}$ Laboratory of Functional Neurosciences (EA 4559), University Hospital of Amiens and University of Picardie Jules Verne, Amiens, France

Corresponding author:

Monica N. Toba PhD

CHU Amiens Picardie - Site Sud, Centre Universitaire de Recherche en Santé, Avenue René Laënnec, 80054 Amiens Cedex 1, France.

E-mail: monica.n.toba@gmail.com 
A 67-year-old right-handed man, blind since the age of 30 because of double retinal detachment and a self-taught Braille reader, sought help at the medical rehabilitation center of the Pitié-Salpêtrière Hospital, because of pervasive difficulties in finding his way even inside his home. He reported that problems abruptly started after he suffered a traumatic brain injury (TBI), a year and a half before. TBI had caused an extensive right temporal hematoma, extending to the fronto-parietal regions, which was surgically evacuated. The patient declared that after the onset of blindness, but prior to the TBI, he had successfully learnt to navigate in familiar and novel environments, "au centimètre près" (to the centimeter), by using a white cane. For example, every day he used to go to his workplace on his own.

After TBI and subsequent neurosurgery, neurological examination disclosed a left hemiparesis that recovered after rehabilitation. The patient then discovered his navigation deficit, when he got lost at a familiar junction and was forced to ask for help. He also experienced new difficulties in localizing other people at home, even when they were in the same room.

Five weeks post TBI, family members and medical staff observed mild signs of visuospatial neglect. Neglect signs had resolved by 21 months after TBI. At this time, the patient did not show asymmetries of performance on a modified version (Cerrato et al., 2020) of the baking tray test (Tham \& Tegner, 1996), and on ad hoc tactile version of the line bisection task (Migliaccio et al., 2012). When asked to point straight ahead (Bartolomeo \& Chokron, 1999; Figure 1) he presented a slight leftward deviation with his right hand, but was accurate with his left hand. He also had left ear extinction on dichotic listening, and a mild psychomotor slowing compared to sighted age-matched norms. Vestibular evaluation was normal. At this time, the patient reported that his navigational skills had improved; he could now find his way successfully within a $600 \mathrm{~m}$ radius of his house, but was still unable to navigate in less familiar environments. Despite these deficits, his spatial knowledge seemed preserved. He provided accurate verbal descriptions of maps of his house, of a known neighborhood, of known underground and car routes, and of a holiday apartment rented after the TBI. Because blindness made the use of most typical neuropsychological tests and their norms impossible (Hill-Briggs et al., 2007), we devised ad hoc experiments, in which we asked the patient to follow several routes in the rehabilitation building (which he knew well), and to learn new routes inside the hospital courtyard. The patient was able to localize correctly his right and his left, as well as forward and backward, but nevertheless deviated unpredictably to the right or to the left during walking. When asked to turn around, he often performed incomplete rotations. Thus, he seemed to show inaccurate turning angles, rather than accurate turning followed by inaccurate forward heading. This pattern contrasts with his reported performance pre-TBI, when he could fully compensate 
for blindness in forward motion. When walking in the hospital courtyard, the patient was able to find his way only when semantic information or relevant landmarks were verbally indicated by the examiner. Yet, he was able to accurately describe the corresponding routes during path-planning. We observed path deviations in both narrow and wider spaces. For example, walking along an 8meter long corridor, he deviated between $1^{\circ}$ to $5^{\circ}$ in five trials, four times toward the right and once toward the left. We also asked him to walk straight ahead along a 10-meter long distance in the entrance hall. In five trials, he deviated between $6^{\circ}$ and $24^{\circ}$, four times to the left and once to the right. The patient subjectively reported increased difficulty to navigate in open spaces, perhaps because of the absence of clear landmarks. He also complained of post-TBI difficulties in time estimation. For example, he tended to underestimate the duration of his 2-hour rehabilitation sessions, which he assessed as lasting about half the time.

Structural MRI revealed contusions in the right hemisphere, mainly involving the superior, middle and inferior temporal gyri, and encroaching upon the hippocampal and parahippocampal regions (Table 1). White matter tractography showed complete disconnection of the right inferior fronto-occipital fasciculus and inferior longitudinal fasciculus, and partial disconnection of the right portions of the splenium of the corpus callosum (Figure 2). Of note, the retrosplenial cortex and the cingulum bundle, whose damage is often associated to navigation impairments (Vann et al., 2009), were spared.

The presence of blindness in this patient, with the associated impossibility to use standard testing (Hill-Briggs et al., 2007), makes it difficult to unequivocally classify his navigation impairments. However, the preserved ability to describe maps and to process landmarks, suggests an impaired integration of egocentric and allocentric spatial information with non-visual modalities and motor feedback (see Aguirre \& D’Esposito, 1999). This may have led to impaired 'dead reckoning' (or path integration). General attention problems with subsequent compromised integration capacities would seem unlikely, given the lack of attentional impairment on concurrent neuropsychological examination, and the patient's self-report of being concentrated on the navigation tasks. The behavioral pattern we observed might result from the substantial white matter damage underlying the temporal structures, which was likely to disconnect the medial temporal lobe. Such a disconnection might affect the transfer of high-level spatial information from the hippocampal complex to other networks involved in non-visual heading processing, such as the parietal cortex (Chen et al., 2013; Wolbers et al., 2007). Hippocampal-parietal communication may be critical to select the most appropriate route between two points, and for producing a route-based positional signal (Nitz, 2009). We cannot rule out an additional contribution of the patient's hippocampal and 
parahippocampal lesions. However, these lesions were small (7.3\% and 0.8\% lesioned, respectively; see Table 1). The relative sparing of middle temporal lobe structures might account for preserved spatial knowledge in this patient.

Our patient's pattern of performance is reminiscent of the case report of a sighted patient who had similar difficulties after a stroke in the right medial occipito-temporal region (Mendez \& Cherrier, 2003). This patient was accurate in drawing maps, describing familiar routes and recognizing familiar landmarks, but was unable to identify familiar scenes in the absence of major landmarks. However, vision could have helped this patient to compensate partially for his navigation impairments, thanks to the preserved processing of visual landmarks. By contrast, in the absence of vision, path representation based on vestibular, proprioceptive and tactile signals is likely to be a more serial and error-prone process. The present case allowed us to isolate 'pure' navigation-related processes (Claessen and van der Ham, 2017), and to infer their possible neural basis in circuits involving the medial temporal and parietal cortex in the right hemisphere.

To our knowledge, this is the first reported case of a late-blind patient losing navigation skills after right hemisphere damage. The fact that the core navigation deficit, i.e., deviations from trajectory, was still present 2 years post TBI suggests that his partial recovery relied on compensatory strategies involving non-visual landmarks, and on preserved processing of allocentric spatial information. This interpretation must, however, remain speculative because of the dearth of appropriate testing tools for the neuropsychological evaluation of blind persons (Hill-Briggs et al., 2007). 
Table 1. Percentage of lesion on grey matter regions in the right hemisphere (computations were performed with the AAL template, Tzourio-Mazoyer et al., 2002).

\begin{tabular}{|c|c|}
\hline Region & \% lesion \\
\hline Insula & 2.7 \\
\hline Hippocampus & 7.3 \\
\hline Parahippocampal cortex & 0.8 \\
\hline Occipital Middle & 0.2 \\
\hline Occipital Inferior & 0.1 \\
\hline Fusiform gyrus & 3.2 \\
\hline Angular gyrus & 0.8 \\
\hline Putamen & 0.4 \\
\hline Thalamus & 0.5 \\
\hline Heschl's gyri & 3.1 \\
\hline Temporal Superior & 28.2 \\
\hline Temporal Pole Superior & 2.6 \\
\hline Temporal Middle & 58.5 \\
\hline Temporal Pole Middle & 13.5 \\
\hline Temporal Inferior & 44.9 \\
\hline
\end{tabular}




\section{Figure captions}

Figure 1. Example of the ad hoc material used in order to assess pointing. Patient's right or left index was placed 5 times at $30^{\circ}, 15^{\circ}$ or $0^{\circ}$ (midline aligned) respectively and the patient was asked to point straight ahead. Deviation was measured for each index-starting position for the right and the left hand respectively.

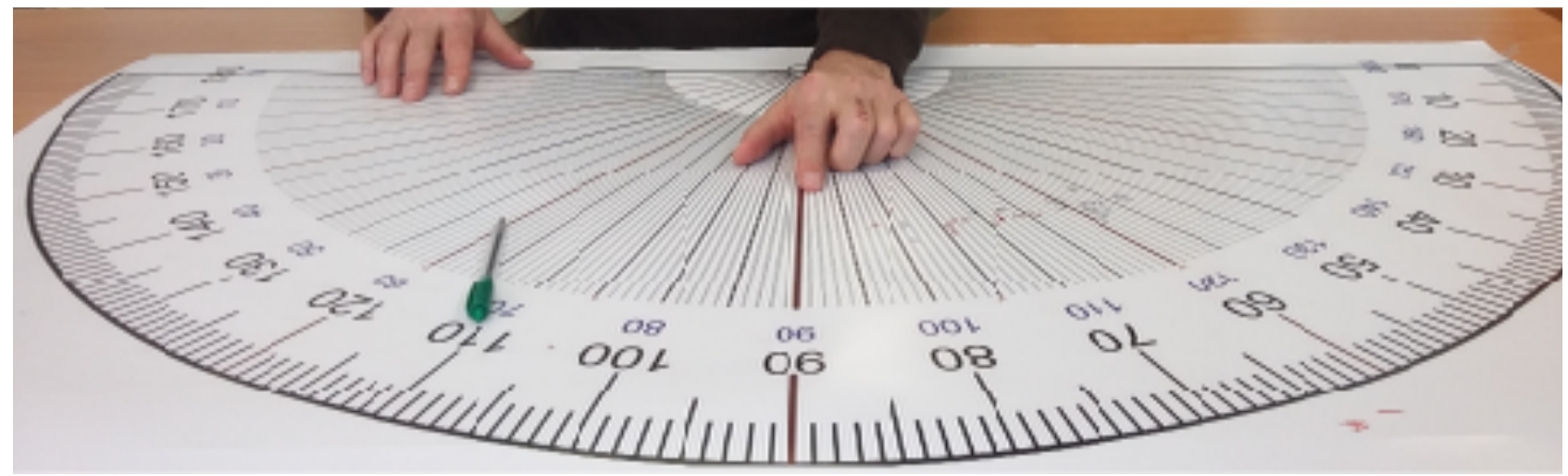

Figure 2. The patient's brain lesion.

A. Depiction of the patient's lesion in the T1-image in native space, involving principally the temporal lobe and extending to fronto-parietal regions. B. Reconstruction of white matter tracts in na tive space showing complete disconnections of the inferior fronto-occipital and the inferior longitudinal fasciculi in the right hemisphere, and partial splenial disconnection of the corpus callosum. Note the disconnection of the callosal splenium seen in both axial and coronal slices. R, right; L, left.

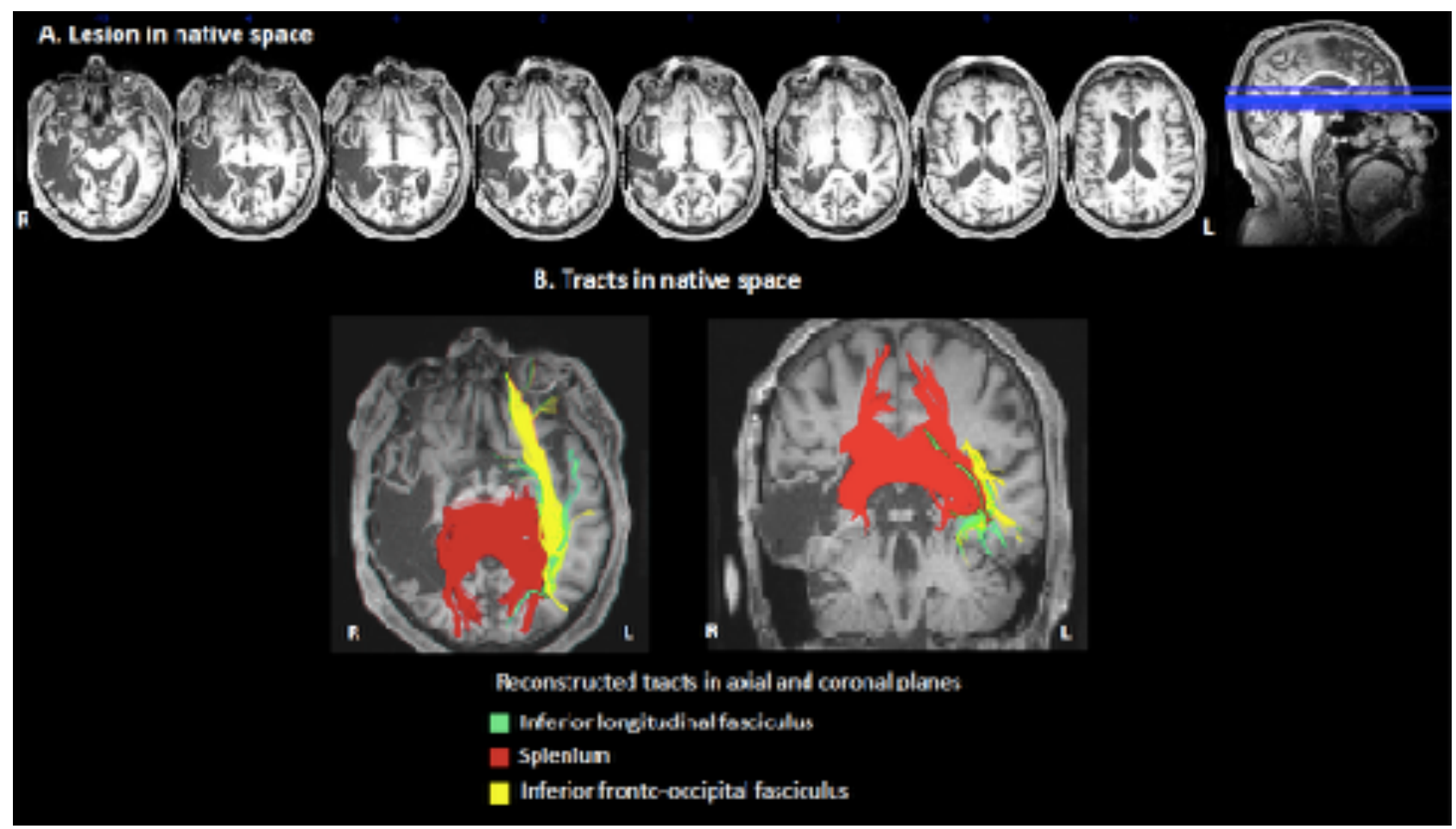




\section{References}

Aguirre, G. K., \& D'Esposito, M. (1999). Topographical disorientation: a synthesis and taxonomy. Brain, 122(9), 1613-1628.

Bartolomeo, P., \& Chokron, S. (1999). Egocentric frame of reference: Its role in spatial bias after right hemisphere lesions. Neuropsychologia, 37(8), 881-894.

Cerrato, A., Pacella, D., Palumbo, F., Beauvais, D., Ponticorvo, M., \& Miglino, O., et al. (2020). ETAN, a technology-enhanced platform with tangible objects for the assessment of visual neglect: A multiple single-case study. Neuropsychological Rehabilitation. doi:10.1101/849505. In press.

Chen, X., DeAngelis, G. C., \& Angelaki, D. E. (2013). Diverse spatial reference frames of vestibular signals in parietal cortex. Neuron, 80(5), 1310-1321.

Claessen, M. H., \& van der Ham, I. J. (2017). Classification of navigation impairment: A systematic review of neuropsychological case studies. Neuroscience \& Biobehavioral Reviews, 73, 81-97.

Hill-Briggs, F., Dial, J. G., Morere, D. A., \& Joyce, A. (2007). Neuropsychological assessment of persons with physical disability, visual impairment or blindness, and hearing impairment or deafness. Archives of clinical neuropsychology, 22(3), 389-404.

Mendez, M. F., \& Cherrier, M. M. (2003). Agnosia for scenes in topographagnosia. Neuropsychologia, 41(10), 1387-1395.

Migliaccio, R., Agosta, F., Toba, M. N., Samri, D., Corlier, F., De Souza, L. C., ... \& Filippi, M. (2012). Brain networks in posterior cortical atrophy: a single case tractography study and literature review. Cortex, 48(10), 1298-1309.

Nitz, D. (2009). Parietal cortex, navigation, and the construction of arbitrary reference frames for spatial information. Neurobiology of learning and memory, 91(2), 179-185.

Tham, K, \& Tegner, R (1996). "The baking tray task: A test of spatial neglect”. Neuropsychological Rehabilitation, 6(1), 19-25. doi:10.1080/713755496.

Tzourio-Mazoyer, N., Landeau, B., Papathanassiou, D., Crivello, F., Etard, O., Delcroix, N., ... \& Joliot, M. (2002). Automated anatomical labeling of activations in SPM using a macroscopic anatomical parcellation of the MNI MRI single-subject brain. Neuroimage, 15(1), 273-289.

Vann, S. D., Aggleton, J. P., \& Maguire, E. A. (2009). What does the retrosplenial cortex do?. $N a-$ ture reviews neuroscience, 10(11), 792-802.

Wolbers, T., Wiener, J. M., Mallot, H. A., \& Büchel, C. (2007). Differential recruitment of the hippocampus, medial prefrontal cortex, and the human motion complex during path integration in humans. Journal of Neuroscience, 27(35), 9408-9416. 